\title{
TrunkDiseaseID.org: A molecular database for fast and accurate identification of fungi commonly isolated from grapevine wood
}

\author{
Daniel P. Lawrence a , Renaud Travadon a , Mizuho Nita ${ }^{\mathrm{b}}$, Kendra Baumgartner ${ }^{\mathrm{c}, *}$ \\ a Department of Plant Pathology, University of California, Davis, CA 95616, USA \\ ${ }^{\mathrm{b}}$ Virginia Polytechnic Institute and State University, AHS Jr. Agricultural Research and Extension Center, Winchester, VA 22602, USA \\ ${ }^{\mathrm{c}}$ United States Department of Agriculture - Agricultural Research Service, Davis, CA 95616, USA
}

\section{A R T I C L E I N F O}

\section{Article history:}

Received 12 May 2017

Received in revised form

17 August 2017

Accepted 19 August 2017

Available online 30 August 2017

\section{Keywords:}

Species diagnosis

Fungi

Grapevine trunk disease

Vitis vinifera

Wood canker

\begin{abstract}
A B S T R A C T
The grapevine trunk-disease complex limits vineyard longevity in all major grape-growing regions. Although trunk diseases have been distinguished based on etiologies (e.g., Botryosphaeria-, Eutypa-, and Phomopsis dieback, Esca) and causal agents, mixed infections of trunk pathogens and other woodcolonizing fungi are frequent in grapevines. These diverse fungal communities in grapevine span four classes in the Pezizomycotina (Ascomycota) and 10 genera in the Hymenochaetales (Basidiomycota). Traditional identification based on morphology is largely untenable because of overlap in colony characteristics or spore dimensions, or lack of sporulation in culture. When based on DNA sequencing, searches of uncurated, public molecular databases can lead to misidentifications. The new molecular database TrunkDiseaseID.org is populated with accurate rDNA ITS sequences from $250+$ isolates (pathogens and saprobes) and secondary DNA barcodes for delineating closely related species. Currently, no such comprehensive database exists for grapevine wood-colonizing fungi. In addition to ITS and secondary barcode sequences, this database provides a scientific reference, origin, and ecological status for each isolate, to aid diagnosticians in communicating results and recommendations to growers. Outreach through the National Plant Diagnostic Network and the US Department of Agriculture's Identification Technology Program will connect diagnosticians to this new database for grape.
\end{abstract}

Published by Elsevier Ltd.

\section{Introduction}

Grapevine trunk diseases impact grape production worldwide (Bertsch et al., 2013). The causal agents (aka trunk pathogens) constitute a complex of fungi mainly belonging to the filamentous Ascomycota; Pezizomycotina. In vineyards, most infections are thought to be initiated by fungal spores germinating on pruning wounds and other wounds to the vine's permanent woody structure (i.e., the trunk, cordons, and spurs) (Petzoldt et al., 1981; Serra et al., 2008; Úrbez-Torres and Gubler, 2011). These infections develop internally and can appear either as dark discoloration in the secondary xylem, a common wood symptom of the trunk disease Esca (Mugnai et al., 1999), or as a necrotic wood canker, a common wood symptom of Botryosphaeria-, Eutypa-, and Phomopsis diebacks (Fig. 1A and B) (Kuntzmann et al., 2010). Trunk diseases limit yields by either killing fruiting positions (i.e., spurs;

\footnotetext{
* Corresponding author.

E-mail address: Kendra.Baumgartner@ars.usda.gov (K. Baumgartner).
}

Fig. 1C), damaging the vascular connection between the shoots and roots, or delaying fruit ripening (Lorrain et al., 2012). Trunk diseases cause severe reductions in the long-term profitability of vineyards (Kaplan et al., 2016), and often necessitate replanting (Sipiora and Cuellar, 2014).

Field identification of individual trunk diseases is problematic because symptoms, such as dead spurs (Fig. 1C) and dead cordons, are shared by Botryosphaeria-, Eutypa-, and Phomopsis dieback. Among these dieback-type diseases, Eutypa dieback causes diagnostic foliar symptoms (Fig. 1D), but they are ephemeral and their expression depends on environmental factors (Sosnowski et al., 2007). The foliar symptoms of Esca (Fig. 1E) and especially the fruit symptoms are diagnostic, but symptom expression varies from vine-to-vine on an annual basis (Marchi et al., 2006). While such characteristics make accurate field diagnosis of trunk diseases a serious challenge, there are also numerous fungi present in grapevine wood that confound identification of the main causal agents (Travadon et al., 2016). For example, the main Esca pathogens are the ascomycete fungi Phaeomoniella chlamydospora (W. Gams, Crous, M.J. Wingf. \& Mugnai) Crous \& W. Gams, 


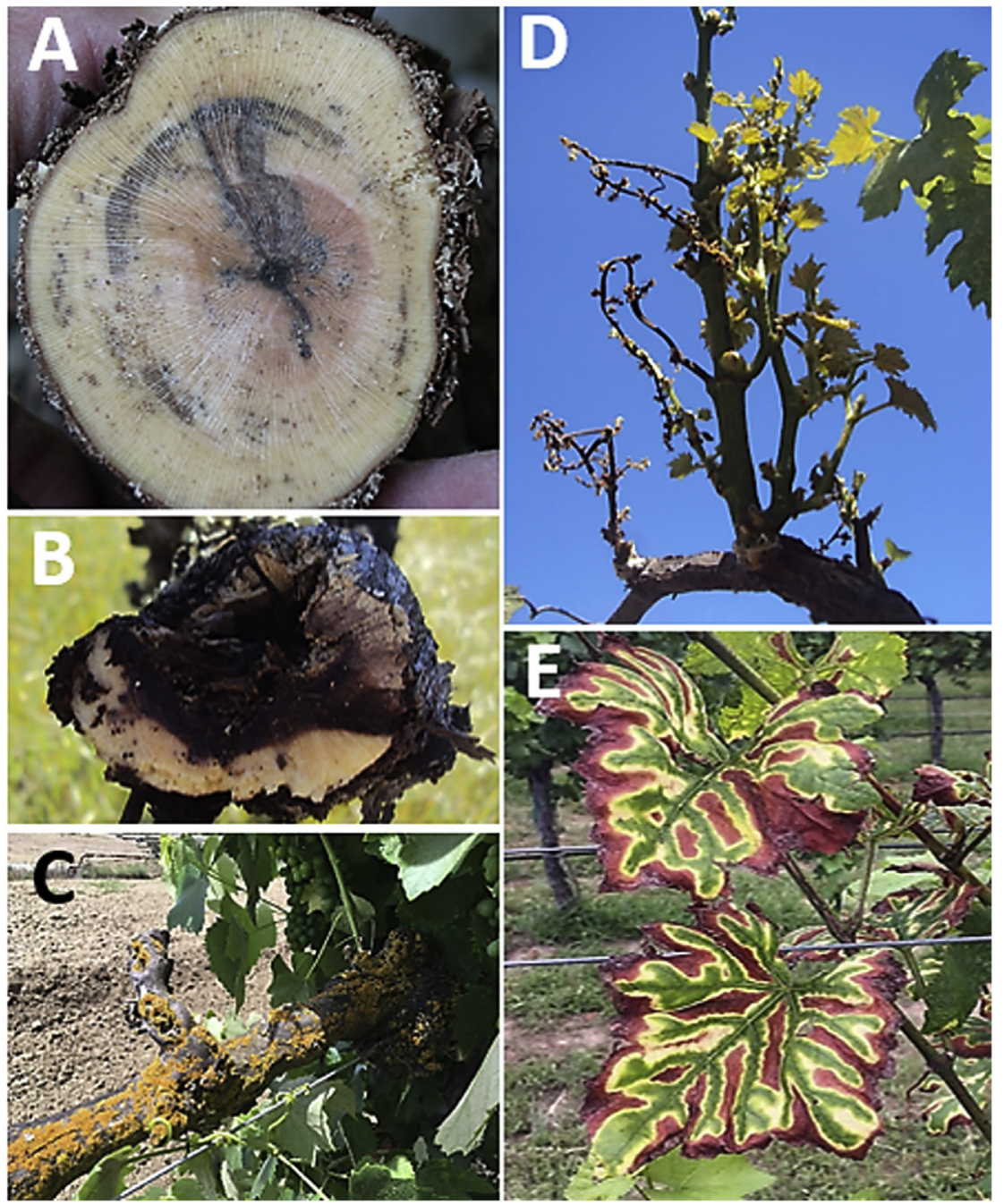

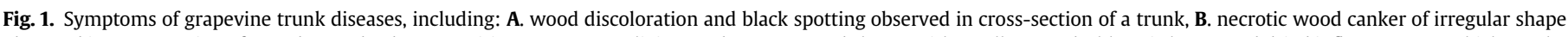

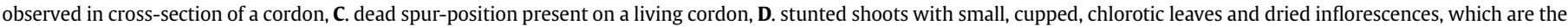
foliar symptoms of Eutypa dieback, and $\mathbf{E}$. foliar symptom of Esca.

Phaeoacremonium minimum (Tul. \& C. Tul.) D. Gramaje, L. Mostert \& Crous, and other Phaeoacremonium W. Gams, Crous \& M.J. Wingf. species (Gramaje et al., 2015). Vines at an advanced stage of Esca may be further infected by basidiomycete fungi, isolates of which represent ten genera within the Hymenochaetales (Cloete et al., 2015), namely Fomitiporia mediterranea M. Fisch. (Fischer, 2006). These basidiomycetes are relatively conspicuous, in terms of extensive decay columns and macroscopic spore-bearing structures, features that can obscure accurate identification of the ascomycete trunk pathogens.

The name of a species or a genus is perhaps one of the most important aspects of taxonomy because it allows for communication of information about organisms and predictions concerning their biology (Rossman and Palm-Hernández, 2008). Scientific names change over time with new knowledge of fungal biology, such as morphology, host and geographical associations, and DNAbased phylogenetic position. DNA-based species identification has now become the norm for many genera [e.g., Fusarium Link (Geiser et al., 2004) and Phytophthora de Bary (Grunwald et al., 2011)]. This approach provides fast and accurate identification when the query is compared against a database populated with reliable and vetted sequences. GenBank, the nucleotide database maintained by the US National Center for Biotechnology Information (NCBI), is an excellent resource for scientists, but serious problems persist, such as submission of sequences that are of poor quality (Harris, 2003) or sequences that contain annotation errors (Bidartondo et al., 2008). Nilsson et al. (2006) estimates approximately $20 \%$ of fungal entries in GenBank may be erroneously identified to the species-level, thus complicating accurate species identification.

We developed TrunkDiseaseID, a publicly available, curated molecular database for diagnosticians, who must rapidly process grapevine samples from growers, pest-control advisers, extension agents, and nurseries accurate identification of trunk pathogens to the species-level. TrunkDiseaseID can be used by taxonomists or systematists. However, it is a resource designed for diagnosticians, who have the following constraints not shared with academic labs: 
paying customers who expect timely results, limited access to primary literature, and staff who are not trained scientists. Grapevine trunk diseases are one of the most thoroughly characterized disease complexes (Lamichhane and Venturi, 2015), hence our focus on grape and not other horticultural crops. Because trunk diseases have numerous causal fungi, it is unrealistic to expect growers to be familiar with the scientific names. As such, TrunkDiseaseID is populated with pathogenicity test results of species commonly isolated from grapevine wood. In this way, when growers submit a sample for disease diagnosis and a species name is returned to them, they can make management decisions based in part on whether the species is a known pathogen. Indeed, diagnostic labs typically provide a measure of disease risk along with a positive test result for other grape pathogens (e.g., grapevine rootstock susceptibility to Meloidogyne incognita, root-knot nematode), to help growers evaluate the findings.

Here we describe the structure of TrunkDiseaseID and provide instructions on its use. TrunkDiseaseID is not a new diagnostic assay, but instead is meant to improve the accuracy of, and thus encourage adoption of, molecular identification. This approach is needed for trunk diseases because reliance on morphological characters is unlikely to provide an accurate or timely species diagnosis. Some trunk pathogens are recalcitrant to production of ascomata/conidiomata in culture, and even for those that do sporulate, colony and spore morphology may be strongly influenced by culture conditions (Pennycook and Samuels, 1985) [e.g., temperature (Slippers et al., 2004)]. In the absence of standard assays for trunk-disease diagnosis, therefore, we implemented peer evaluation of the database based on a questionnaire sent to diagnostic labs and based on our own comparisons of GenBank versus TrunkDiseaseID.

\section{Materials and methods}

\subsection{TrunkDiseaseID data and application}

TrunkDiseaseID is a user-friendly web-based platform for fast and accurate BLAST searches, utilizing the primary fungal rDNA internal transcribed spacer region (ITS) barcode and secondary 'group-specific' barcodes (e.g., EF1- $\alpha$ for the Botryosphaeriaceae, Diaporthaceae, Helotiales, and Hypocreales; and $\beta$-tubulin (TUB2) for the Diatrypaceae and Togniniaceae), representing fungi that have been isolated in culture from symptomatic grapevine wood. The database includes ITS and secondary DNA barcode sequences for all available grapevine trunk pathogen specimens, including additional isolates for the most common grapevine trunk pathogens in GenBank. We recognize that a single locus may not discriminate all species, hence our inclusion of secondary 'groupspecific' barcodes in TrunkDiseaseID, which are often found to be more informative (i.e., variable) than ITS in distinguishing some genera or species of trunk pathogens [e.g., $\beta$-tubulin (Úrbez-Torres et al., 2015)].

We provide 471 vetted nucleotide sequences corresponding to a wide range of isolates (283 total) representing 245 fungal species from varying geographical locations ( 35 countries from all continents except Antarctica). For the following species of trunk pathogens, which are known to exhibit high levels of intraspecific variation, multiple isolates were included in order to represent this genetic variation in the database: Diaporthe eres Nitschke (Gomes et al., 2013), Eutypa lata (Pers.) Tul. \& C. Tul. (Trouillas et al., 2010), Lasiodiplodia theobromae (Alves et al., 2008), and Neofusicoccum parvum (Sakalidis et al., 2013). Also, the database includes species that exhibit low levels of interspecific variation: $N$. parvum and $N$. ribis (Sakalidis et al., 2011), and closely related species/hybrids of Lasiodiplodia (Cruywagen et al., 2017). Such species/isolates have been assessed via extensive literature review (67 references) and phylogenetic analyses to ensure accurate identification and phylogenetic position with ex-type sequences.

To accommodate diagnostic labs that may not have access to university libraries, nor the time to pore over the primary literature, each entry contains a comprehensive set of information: host, geographic origin, NCBI Accession number (linked to NCBI), and ITS or secondary barcode sequence and PCR primers. Species are categorized as pathogen, non-pathogen, or of unknown/untested ecology. References to the published results of pathogenicity tests conducted in research laboratories around the world represent 85 sources of primary literature. Citations are provided for PCR conditions associated with primers, species identities and distributions, and pathogenicity tests. Our intent in pooling this information in TrunkDiseaseID is to expedite the response time at the diagnostic lab, from the start of sample processing to species identification and making a recommendation to growers, extension agents, and pest-control advisers.

An open source content management system, Drupal v. 8 (Drupal Association, Portland, OR, USA), was used as a platform for the database. The function for the local BLAST search was achieved by installing BLAST v. 2.2.28+ (http://www.ncbi.nlm.nih.gov) to a remote Linux server, which hosts the database. The content management system (Drupal) was used to develop the interface for both end users and administrators, to manage data in the database, and to submit queries to both local and NCBI BLAST searches.

The web-based platform allows users to query the database with unknown ITS or secondary barcode sequences. Almost half of the ITS sequences (47\%) have been generated by our research group and vetted for accuracy by comparing with ex-type or representative specimen sequences; the remaining sequences were collected via extensive literature review of grapevine trunk pathogens from other continents. We focus on the most widespread grapevine trunk pathogens (Fig. 2). Species are members of the family Sporocadaceae (Sordariomycetes, Amphisphaeriales), including Pestalotia-like genera Pestalotiopsis Steyaert, Neopestalotiopsis Maharachch., K.D. Hyde \& Crous, Seimatosporium Corda, and Truncatella Steyaert; members of the Botryosphaeriaceae (Dothidiomycetes, Botryosphaeriales), including the genera Botryosphaeria Ces. \& De Not., Diplodia Fr., Dothiorella Sacc., Lasiodiplodia Ellis \& Everh., Neofusicoccum Crous, Slippers \& A.J.L. Phillips, and Neoscytalidium Crous \& Slippers; members of the Diatrypaceae (Sordariomycetes, Xylariales), including the genera Cryptosphaeria Ces. \& De Not., Cryptovalsa Ces. \& De Not. Ex Fuckel, Diatrype Fr., Diatrypella (Ces. \& De Not.) De Not., Eutypa Tul. \& C. Tul., and Eutypella (Nitschke) Sacc.; members of the Togniniaceae (Sordariomycetes, Diaporthales), including species of Phaeoacremonium; members of the Diaporthaceae and Cytosporaceae (Sordariomycetes, Diaporthales), including species of Diaporthe Nitschke and Cytospora, respectively; members of the Phaeomoniellaceae (Eurotiomycetes, Phaeomoniellales), including $\mathrm{NeO}$ phaeomoniella Rooney-Latham \& Crous and Phaeomoniella Crous \& W. Gams. We include pathogenic taxa that are less common, such as members of Cadophora (Leotiomycetes, Helotiales) and Campylocarpon Halleen, Schroers \& Crous, Dactylonectria L. Lombard \& Crous, and Ilyonectria P. Chaverri \& C. Salgado (Sordariomycetes, Hypocreales), and commonly encountered non-pathogenic woodcolonizing fungi, such as Alternaria Nees (Dothidiomycetes, Pleosporaceae), Chaetomium Kunze (Sordariomycetes, Sordariales), and Trichoderma Pers. (Sordariomycetes, Hypocreaceae). Lastly, we include fungi with unknown/untested ecology [e.g., Fusarium 

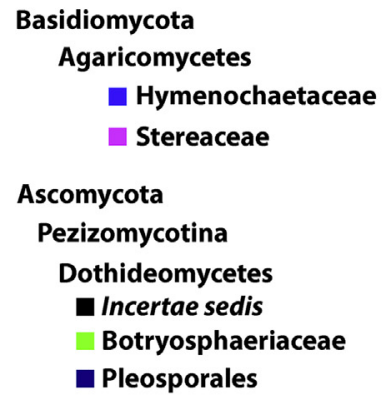

Eurotiomycetes Trichocomaceae

Phaeomoniellaceae

Leotiomycetes Helotiales

Sordariomycetes

Sporocadaceae

Diaporthales

Diaporthaceae

Cytosporaceae

- Togniniaceae

Xylariales

Diatrypaceae

Hypocreales

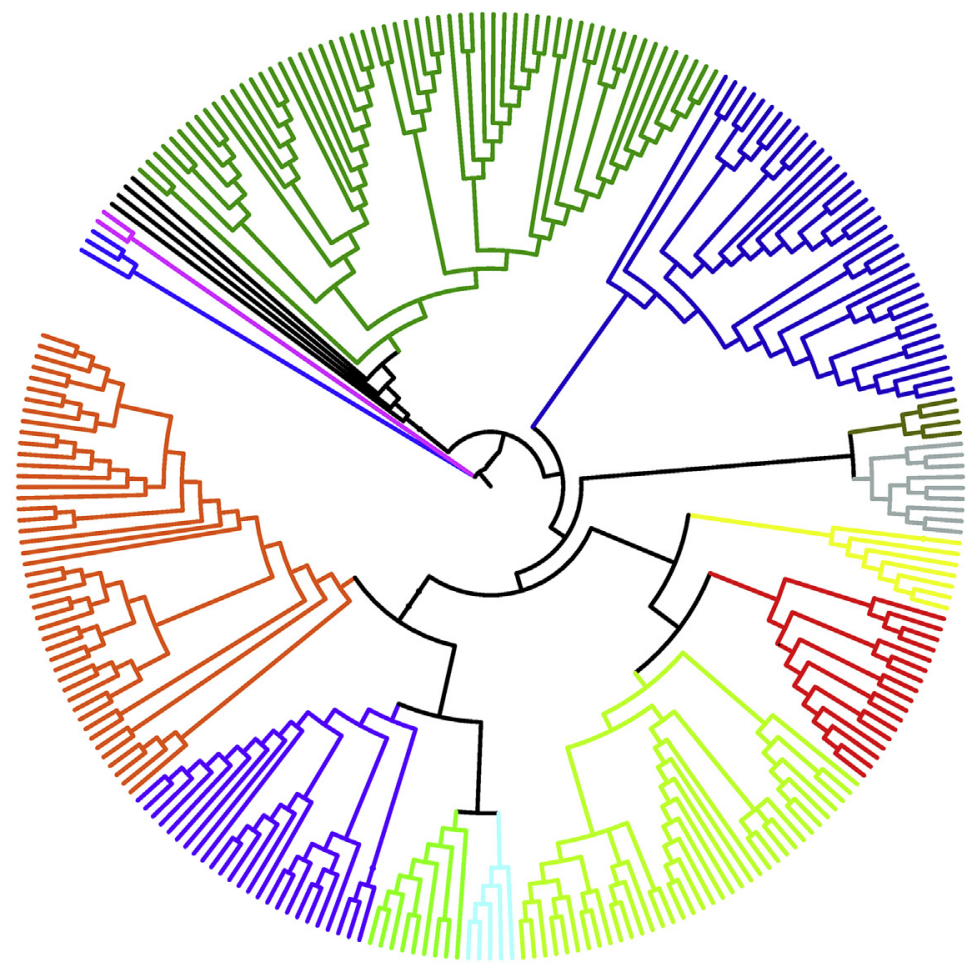

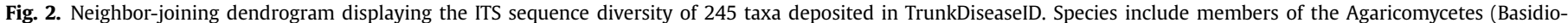
mycota) and the Pezizomycotina (Ascomycota).

(Sordariomycetes, Nectriaceae)], which have been isolated from symptomatic or asymptomatic grapevine wood.

\subsection{PCR and sequencing}

For sequences generated by our research group, genomic DNA was isolated from aerial mycelium of 7- to 14-day-old axenic cultures using the DNeasy Plant kit (Qiagen), following manufacturer's instructions. Amplification of ribosomal DNA (rDNA), including the intervening internal transcribed spacer regions and 5.8S rDNA (ITS1-5.8S-ITS2), was performed using the forward primers ITS5 or ITS1 and the reverse primer ITS4, following the protocol of White et al. (1990). Group-specific barcodes were generated by sequencing portions of protein-coding genes: EF1- $\alpha$ using the primers EF1-688F and EF1-1251R (Alves et al., 2008) or EF1-728F and EF1-986R (Carbone and Kohn, 1999), and TUB2 using primers T1 (O'Donnell and Cigelnik, 1997) and Bt2b (Glass and Donaldson, 1995). For sequences generated by other research groups and deposited in GenBank, DNA extraction procedures and PCR primers are detailed in the publications associated with each taxon (see 'Reference' under 'Isolate info' section of the website). PCR products were visualized on a $1.5 \%$ agarose gel ( $120 \mathrm{~V}$ for $25 \mathrm{~min}$ ) to validate presence and size of amplicons, followed by purification via Exonuclease I and recombinant Shrimp Alkaline Phosphatase (Affymetrix, Santa Clara, CA, USA), and sequenced bidirectionally on an ABI 3730 Capillary Electrophoresis Genetic Analyzer (College of Biological Sciences Sequencing Facility, University of California, Davis). Forward and reverse reads were assembled, proofread, and edited in Sequencher v. 5 (Gene Codes Corporation, Ann Arbor, MI, USA) and deposited in GenBank (KU721856-KU721884 and KY031519-KY031533). PCR products for ITS generally ranged in size from 400 to 605 nucleotides for most fungi examined.

\subsection{Interpretation of BLAST results and validation of database}

The use of TrunkDiseaseID is similar to other BLAST databases, whereby the sequence of interest is pasted in text file format into a search window and used to query the database (Fig. 3A). After submitting a query, TrunkDiseaseID returns a table that displays the following BLAST results (Fig. 3B): top BLAST matches, host plant, ecology (if known), NCBI\#, score (bits), E-value, and percent identity. By selecting the name of a species in the table of top BLAST matches, the user is directed to a set of additional information (scientific reference, NCBI accession number linked to NCBI) specific to the isolate representing the species (Fig. 3C). Users may also view the detailed output from BLAST (as appears in the format of a BLAST search of GenBank), consisting of a series of DNA alignments between the query sequence and those of the top BLAST matches, which can be visually inspected for polymorphic or invariant sites.

Like all BLAST analyses, care must be taken to ensure that conclusions are as accurate and meaningful as possible by taking all BLAST results into account. In general, the top BLAST match is the best estimation of species identity, which is based on percent identity between the query and the database. Nonetheless, additional parameters must be carefully evaluated to ensure the best possible result. BLAST scores may be heavily influenced by the percent identity and percent query coverage scores. For example, an erroneous interpretation may identify species " $\mathrm{X}$ " as species " $\mathrm{Y}$ " (a false positive) because of low query coverage, resulting in high sequence identity, especially for highly conserved regions (e.g., the $5.8 \mathrm{~S}$ region of ITS or exons of protein-coding genes) among related and unrelated taxa. As such, species identity should be based on a combination of nearly complete query coverage ( $\geq 99 \%$ ), a sequence identity of $\geq 99 \%$, a high bit score (relative to others), and an E-value score very near zero.

To ensure that the steps of the BLAST search and navigating the website were sufficiently detailed, we developed a questionnaire 


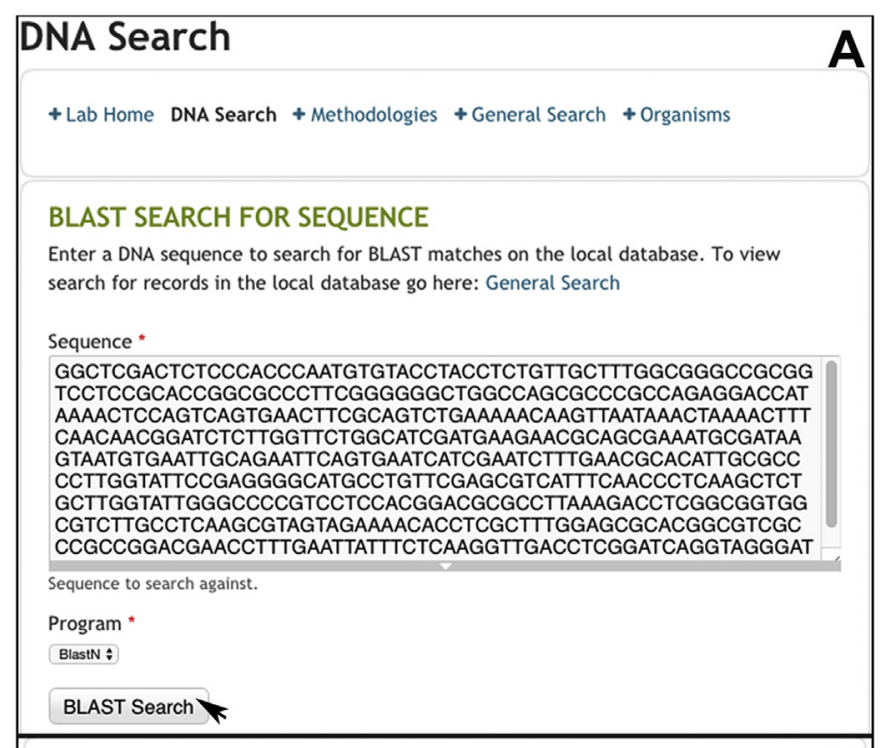

BLAST SEARCH FOR SEQUENCE

Enter a DNA sequence to search for BLAST matches on the local database. To view search for records in the local database go here: General Search

Performing BLAST search for sequence beginning with GCTCGACTCTCCCACCCAATGTGT... Assembled fasta file with 266 records.

View Detailed Output from BLASTLocal Database Matches:

\begin{tabular}{|c|c|c|c|c|c|c|}
\hline BLAST match & Host plant & Ecology & $\begin{array}{l}\text { Score } \\
\text { (bits) }\end{array}$ & E-value & $\begin{array}{c}\text { Query } \\
\text { Coverage }\end{array}$ & Identity \\
\hline Neofusicoccum paryum & grape & pathogen & 1051.0 & $1 e-300$ & $100 \%$ & $100 \%$ \\
\hline Neofusicoccum ribis & currant & pathogen & 938.0 & $1 e \cdot 300$ & $100 \%$ & $99 \%$ \\
\hline $\begin{array}{l}\text { Neofusicoccum } \\
\text { mediterraneum }\end{array}$ & eucalyptus & pathogen & 930.0 & $1 \mathrm{e} \cdot 300$ & $100 \%$ & $97 \%$ \\
\hline $\begin{array}{l}\text { Neofusicoccum } \\
\text { australe }\end{array}$ & grape & pathogen & 904.0 & $1 e-300$ & $100 \%$ & $96 \%$ \\
\hline
\end{tabular}

ISOLATE INFO

Edit

Isolate Code: UCR-NP2

Fungal Species Name: Neofusicoccum parvum

Ecology: pathogen

Host Common Name: grape

Reference:

Blanco-Ulate, B., Rolshausen, P. E., and Cantu, D. 2013. Draft genome sequence of Neofusicoccum

parvum isolate UCR-NP2, a fungal vascular pathogen associated with grapevine cankers. Genome

Announcements 1:e00339-13.

NCBI Accession number: KU721857

Locus: ITS

Sequence: GGGGGCTGGCCAGCGCCCGCCAGAGGACCATAAAACTCCAGTCAGTGAACTTCGCAGTCTGAAAAACAAGTTAATAAA CTAAAACTTTCAACAACGGATCTCTTGGTTCTGGCATCGATGAAGAACGCAGCGAAATGCGATAAGTAATGTGAATTG CAGAATTCAGTGAATCATCGAATCTTTGAACGCACATTGCGCCCCTTGGTATTCCGAGGGGCATGCCTGTTCGAGCGT CATTTCAACCCTCAAGCTCTGCTTGGTATTGGGCCCCCGTCCTCCACGGACGCGCCTTAAAGACCTCGGCGGTGGCGTC TTGCCTCAAGCGTAGTAGAAAACACCTCGCTTTGGAGCGCACGGCGTCGCCCGCCGGACGAACCTTTGAATTATTTCT CAAGGTTGACCTCGGATCAGGTAGGGATACCCGCTGAACTTAAGCATATCAATAAGCCGGAGG

Forward Primer Name: ITS-1

Reverse Primer Name: ITS-4

Fig. 3. Series of screen shots illustrating the steps of a BLASTn search in TrunkDiseaseID: $A$. on the DNA search page, paste ITS sequence of unknown fungal isolate into sequence window and select BLAST Search (see arrow), B. TrunkDiseaseID returns a table displaying the top BLAST matches, with ITS of Neofusicoccum parvum (in this example) as the best match, in terms of having the highest bit score and $100 \%$ identity, compared to ITS of the two other $N$. parvum isolates shown. An asterisk in the percent identity column represents a putative BLAST match, and a recommendation appears regarding the use of secondary barcodes to provide a more accurate identification. $\mathbf{C}$. By selecting 'Neofusicoccum parvum' in the table (see arrow), a detailed list of 'Isolate Info', C, is provided.

testing a respondent's ability to return the correct answer from a search of TrunkDiseaseID, given a DNA sequence. We also asked respondents to test their own sequences, previously identified based on BLAST searches of GenBank. The questionnaire was sent to
10 diagnostic labs in California, three of which responded that they have used DNA sequencing to identify cultures isolated from grapevines with trunk-disease symptoms.

\section{Results and discussion}

\subsection{Trunk pathogens for which molecular identification outperforms culture-based identification}

Culture-based identification of trunk pathogens is relatively straight-forward for the Esca pathogens Phaeomoniella chlamydospora and Phaeoacremonium minimum. These taxa sporulate well in culture and there are good dichotomous keys for narrowing their identities down to the species-level (Mostert et al., 2006). If species-level identification must be verified, BLASTn searches with ITS or secondary barcode sequences of these and related pathogens of grape give definitive results in GenBank. There are dozens of ITS sequences of both species deposited in GenBank.

Culture-based identification of other trunk pathogens is not straight forward. Diaporthe ampelina (Berk. \& M.A. Curtis) R.R. Gomes, Glienke \& Crous [formerly Phomopsis viticola (Sacc.) Sacc.] is one of the most widely distributed and aggressive causal agents of Phomopsis dieback (Úrbez-Torres et al., 2013). Distinguishing the other Diaporthe species from grape is a challenge because many isolates do not sporulate in culture and, even for those that do, spore morphology cannot distinguish all species that colonize grape (Baumgartner et al., 2013). Diaporthe australafricana is reported from symptomatic vines and is similar to $D$. ampelina in culture morphology, but it does not appear to be a trunk pathogen of grape (Lawrence et al., 2015). BLASTn searches of TrunkDiseaseID or GenBank using an ITS sequence of $D$. australafricana return this species as a top match with $100 \%$ identity, although other GenBank BLAST hits of $100 \%$ identity that have different species names or are unidentified Phomopsis species could potentially lead to an ambiguous diagnostic lab result of 'Diaporthe sp.'. The advantage of TrunkDiseaseID is that in addition to returning only D. australafricana and not also other Diaporthe species as a top BLAST hit, it provides the ecological status of $D$. australafricana, which saves the diagnostician the trouble of hunting down and then reading articles that may or may not include pathogenicity testing on grape. Also morphologically similar to D. ampelina in culture are $D$. chamaeropis, $D$. eres, $D$. foeniculina, and D. nobilis, isolates of which have been shown to have comparable levels of aggressiveness as D. ampelina (Lawrence et al., 2015). Similar to ITS BLASTn searches for $D$. australafricana, TrunkDiseaseID clearly distinguished $D$. chamaeropis, D. foeniculina, and D. nobilis from D. ampelina, whereas GenBank returns other Diaporthe and/or unidentified Phomopsis spp. Diaporthe eres is the only species of this morphologically similar group for which an ITS BLASTn search of GenBank returned $D$. eres as the only species with $100 \%$ identity.

Eutypa lata, causal agent of Eutypa dieback, does not produce sexual fruiting structures in culture, and its asexual spores are not necessarily diagnostic because of the overall similarity of diatrypaceous anamorphs (Glawe and Rogers, 1982). However, variation in anamorphic characters have sometimes been taxonomically useful in this group of fungi (Glawe and Rogers, 1986). Nonetheless, E. lata may be over-looked by someone without fungal taxonomic expertise, given that mass-hyphal isolates from wood cankers typically will not sporulate unless placed under adequate conditions. Diagnostics is further complicated if that sample is collected outside the short window of time when the distinct foliar symptoms of Eutypa dieback are apparent. Eutypa lata has highly variable ITS sequences (Trouillas and Gubler, 2010), but because GenBank contains dozens of bona fide E. lata ITS sequences, it performs well to distinguish $E$. lata from other Diatrypaceae 
reported from grape (e.g., Diatrype Fr. and Eutypella (Nitschke) Sacc.).

We use Diaporthe species reported from grape and Eutypa lata as examples of how molecular identification can give more accurate results than strictly culture-based identification. Less common genera of trunk pathogens, Cadophora Lagerb. \& Melin (Travadon et al., 2015) and Cytospora Ehrenb. (Lawrence et al., 2017), are characterized as having species with no differences in spore morphology and thus would benefit from a DNA-based approach. The advantage of TrunkDiseaseID over GenBank for such genera that are not widely studied is that there are very few sequences publically available and, thus, TrunkDiseaseID helps target a BLASTn search toward an accurate species name.

\subsection{Queried ITS sequence is $100 \%$ identical to those of $>1$ species}

Low interspecific variation in ITS can lead to multiple BLAST hits for a sequence. When the query and top BLAST match are $100 \%$ identical, they are generally considered the same species. However, it is possible for phylogenetically distinct species to have $100 \%$ identical ITS sequences, even though they are recognized as independent lineages based on the Genealogical Concordance Phylogenetic Species Recognition (GCPSR) (Taylor et al., 2000) using other more variable loci (e.g., EF1- $\alpha$ ). A BLASTn search of the ITS sequence of Lasiodiplodia hormozganensis Abdollahz., Zare \& A.J.L. Phillips or L. theobromae in GenBank will yield a result that lists many $L$. theobromae isolates. The same search of TrunkDiseaseID will result in a list of the following three species, which are $100 \%$ identical to L. theobromae: L. brasiliensis, L. hormozganensis, and $L$. laeliocattleyae. An asterisk in the percent identity column for all three species represents a putative BLAST match, and a recommendation appears recommending the use of the secondary barcode translation elongation factor $1-\alpha(E F 1-\alpha)$ as a better estimator of species identity (Fig. 3B).

Identification of L. theobromae in the past was largely ambiguous because it is closely related to other Lasiodiplodia species, in terms of both highly similar ITS sequences and spore morphologies (Alves et al., 2008). Since then, more polymorphic gene regions (namely a large intron in EF1- $\alpha$ ) were employed in phylogenetic analyses to delineate additional species within the $L$. theobromae species complex [e.g., L. missouriana Úrb.-Torr., Peduto \& Gubler (Úrbez-Torres et al., 2012) and L. citricola Abdollahz. Javadi \& A.J.L. Phillips (Carlucci et al., 2015)]. Again, we recognize that a single locus may not discriminate all species, hence our inclusion of secondary 'group-specific' barcodes in TrunkDiseaseID, which are often found to be more informative (i.e., variable) than ITS in distinguishing some genera or species of trunk pathogens [e.g., EF1- $\alpha$ (Úrbez-Torres et al., 2015)].

\subsection{Queried ITS sequence is $\leq 98 \%$ identical to those of $>1$ species}

When ITS sequence identity is $\leq 98 \%$, the top BLAST match should be considered as putative. Several reasons can explain why a sequence is slightly variable as compared to all sequences in the database. First, the query sequence may represent high intraspecific variation within a described species, and such genetic variants may not be yet included in our database. In this case, PCR amplification and BLAST analysis of the secondary group-specific barcode should allow for identification of known species. If the percent identity is less than $97 \%$ we recommend the user utilize GenBank BLASTn before employing phylogenetic analyses incorporating extype sequences, with high sequence identity, for comparison to determine if the GCPSR concept may be invoked. In this way, a newly discovered and unique phylogenetic position may be elucidated by identifying formerly polymorphic sites, which have become fixed in the population through genetic isolation and/or ecological speciation.

The trunk pathogen Diaporthe eres, one of the causal agents of Phomopsis dieback, has been reported to have highly variable ITS sequences (Gomes et al., 2013). Diaporthe eres is part of the D. eres/ D. nobilis complex (Lawrence et al., 2015). TrunkDiseaseID performs better in BLASTn analyses than GenBank by producing a BLAST output that unambiguously identifies $D$. eres isolates as $D$. eres (98.9\% identity), whereas GenBank provides BLAST hits (100\% identity) that are equivocal: top BLAST matches do not return a species name (i.e., Diaporthe sp. or Phomopsis sp.) or GenBank return names of erroneously labeled sequences (i.e., bona fide Diaporthe eres sequences labeled as $D$. vaccinii Shear or D. cotoneastri (Punith.) Udayanga, Crous \& K.D. Hyde in GenBank). An examination of spore morphology from cultures of both $D$. eres and $D$. nobilis showed considerable overlap in dimensions of their $\alpha$ conidia (Lawrence et al., 2015); the state of the knowledge is that these species, at least on grape, are considered part of a species complex until further work is published on more phylogenetically informative gene regions. That said, isolates of both species can be as virulent on grape as D. ampelina (Lawrence et al., 2015). ITS sequences submitted to our database that are found to have a high species identity to either $D$. eres or $D$. nobilis would, thus, give a similar diagnosis of the presence of a trunk pathogen in the sample.

Another reason the query sequence is slightly variable as compared to all sequences in the database is that it may represent an undescribed species that is phylogenetically distinct from the top BLAST match. For example, Diatrype sp. isolate CG14 is included in TrunkDiseaseID because it was isolated from grape wood (Trouillas et al., 2011). A BLASTn search of GenBank and TrunkDiseaseID shows this isolate has ITS and beta-tubulin sequences that are $99 \%$ ( $518 / 523$ base pairs) and $97 \%$ similar (337/346 base pairs), respectively, to those of $D$. brunneospora Trouillas, Sosnowski \& Gubler. Such similarity values are low and, thus, strongly suggest that Diatrype sp. isolate CG14 represents an undescribed species (Trouillas et al., 2011).

\section{Conclusions}

DNA sequencing from cultures or symptomatic wood is only worth the added expense to the diagnostic lab if it is likely to improve accuracy over the common approach of culture-based identification. TrunkDiseaseID fills an important gap between researchers and diagnosticians. It is unique in being populated with carefully annotated sequence data from our own culture collection and from those of other trusted sources, which have been through the peer-review process and thus published in scientific journals. This diagnostic tool summarizes the taxonomy and ecology of trunk pathogens from a very fragmented literature, which is not easily accessible to diagnosticians outside an academic setting. Growers and nurseries send samples to diagnostic labs to determine what is causing trunk-disease symptoms. The diagnostic lab is tasked with identifying a fungal species and providing the grower with some measure of disease risk, which can help control or manage the disease. Labs have variable expertise in fungal identification, and this group of trunk pathogens is a challenge to most mycology research labs. Inclusion of non-pathogenic fungi isolated from grapevine wood will further help diagnosticians distinguish virulent pathogens from fungi that pose little to no threat in the vineyard. Outreach to the National Plant Diagnostic Network (NPDN) and the U. S. Department of Agriculture (USDA) Identification Technology Program (ITP) will connect diagnosticians and practitioners to this new database. The structure of the database allows for updates, to ensure accurate species diagnoses as new DNA sequences are published, as species names are changed, and as 
pathogenicity of wood-colonizing fungi is evaluated. Sequences of novel fungi isolated from grapevine wood can be added to the database by contacting the authors, who will evaluate and integrate new entries. In general, only newly reported species accompanied by a peer-reviewed publication will be added to this expanding resource.

It is important to identify trunk pathogens to the species-level because each individual trunk disease can be caused by several closely related species, which often vary in virulence and geographic range. For example, more than 20 species within the Botryosphaeriaceae are reported from grape, but not all are virulent and some have relatively restricted geographic ranges (ÚrbezTorres, 2011). Distinct timing of sporulation among species, furthermore, affects the efficacy of preventative practices (van Niekerk et al., 2010, 2011). As such, knowledge of the pathogen species (assuming sporulation conditions are also known) can thus help growers synchronize disease prevention with periods of high inoculum pressure. The efficacy of fungicides used to protect pruning wounds from infection varies among trunk pathogen species (Rolshausen et al., 2010). Similarly, the common preventative practice of delayed pruning has been shown to have variable efficacy among trunk pathogens (Larignon and Dubos, 2000; Úrbez-Torres and Gubler, 2011).

Beyond the purpose of species diagnosis through sequencing, we hope that our database may facilitate the identification of species-specific molecular markers and their subsequent incorporation into DNA-based diagnostic tools for trunk pathogens, either for grape or for other horticultural crops. One such tool developed recently for diagnostic labs is a macroarray for detection of trunk pathogens associated with decline of grape nursery stock (ÚrbezTorres et al., 2015). Grapevines propagated from infected mother vines are a source of inoculum in vineyards. Nurseries are tasked with propagating clean plants and, on the other hand, growers are concerned about planting contaminated nursery stock. DNA is extracted from grapevine wood, PCR is used to amplify the fungal $\beta$ tubulin locus, and the PCR products, presumably from a mixed infection, are hybridized to the macroarray. This diagnostic tool eliminates the need for culturing and DNA sequencing because the macroarray includes probes for a comprehensive range of fungi that commonly contaminate nursery stock. In addition to such diagnostic tools that utilize plant tissues, a DNA-based diagnostic tool for use with spore traps would benefit identification of trunkpathogen spores during the pruning season. A spore-trapping approach, which has been tested for other grape pathogens [e.g., powdery mildew (Thiessen et al., 2016)], could help growers assess the risk of infection and adjust accordingly the safest timing for pruning. Regardless of the approach for new diagnostic tools, as the sequences of more trunk-pathogen isolates are added to our database, from different geographic locations, different hosts, and different gene regions, the knowledge of species ecology and distribution will benefit disease management.

\section{Acknowledgements}

We thank A.-L. Fabritius (AL\&L Crop Solutions), F. Trouillas (University of California, Davis), T. Eifler (AgriAnalysis), and S. Rooney-Latham (California Department of Food and Agriculture) for testing TrunkDiseaseID with a plethora of sequences for accurate species identification. We also thank R. Burgholzer at Virginia Tech for technical assistance with database development. Funding: This work was supported by the United States Department of Agriculture, National Institute of Food and Agriculture's Specialty Crops Research Initiative [grant 2012-51181-19954].

\section{References}

Alves, A., Crous, P.W., Correia, A., Phillips, A.J.L., 2008. Morphological and molecular data reveal cryptic speciation in Lasiodiplodia theobromae. Fung. Divers. 28, $1-13$.

Baumgartner, K., Fujiyoshi, P.T., Travadon, R., Castlebury, L.A., Wilcox, W.F., Rolshausen, P.E., 2013. Characterization of species of Diaporthe from wood cankers of grape in eastern North American vineyards. Plant Dis. 97, 912-920.

Bertsch, C., Ramirez Suero, M., Magnin Robert, M., Larignon, P., Chong, J., Abou Mansour, E., Spagnolo, A., Clement, C., Fontaine, F., 2013. Grapevine trunk diseases: complex and still poorly understood. Plant Pathol. 62, 243-265.

Bidartondo, M., Bruns, T.D., Blackwell, M., et al., 2008. Preserving accuracy in GenBank. Science 319, 1616.

Carbone, I., Kohn, L.M., 1999. A method for designing primer sets for speciation studies in filamentous ascomycetes. Mycologia 91, 553-556.

Carlucci, A., Cibelli, F., Lops, F., Raimondo, M.L., 2015. Characterization of Botryosphaeriaceae species as causal agents of trunk diseases on grapevines. Plant Dis. 99, 1678-1688.

Cloete, M., Fischer, M., Mostert, L., Halleen, F., 2015. Hymenochaetales associated with esca-related wood rots on grapevine with a special emphasis on the status of esca in South African vineyards. Phytopathol. Medit. 54, 299.

Cruywagen, E.M., Slippers, B., Roux, J., Wingfield, M.J., 2017. Phylogenetic species recognition and hybridization in Lasiodiplodia: a case study on species from baobabs. Fung. Biol. 121, 420-436.

Fischer, M., 2006. Biodiversity and geographic distribution of Basidiomycetes causing esca-associates white rot in grapevine: a worldwide perspective. Phytopathol. Medit. 45, 30-42.

Geiser, D.M., del Mar Jimenez-Gasco, M., Kang, S., Makalowska, I., Veeraraghavan, N., Ward, T.J., Zhang, N., Kuldau, G.A., O'Donnell, K., 2004. FUSARIUM-ID v. 10: a DNA sequence database for identifying Fusarium. Eur. J. Plant Pathol. 110, 473-479.

Glass, N.L., Donaldson, G.C., 1995. Development of primer sets designed for use with the PCR to amplify conserved genes from filamentous ascomyetes. App. Environ. Microbiol. 61, 1323e1330.

Glawe, D., Rogers, J., 1982. Observations on the anamorphs of six species of Eutypa and Eutypella. Mycotaxon 14, 334-346.

Glawe, D.A., Rogers, J.D., 1986. Conidial states of some species of Diatrypaceae and Xylariaceae. Can. J. Bot. 64, 1493-1498.

Gomes, R.R., Glienke, C., Videira, S.I.R., Lombard, L., Groenewald, J.Z., Crous, P.W. 2013. Diaporthe: a genus of endophytic, saprobic and plant pathogenic fungi. Persoonia 31, 1-41.

Gramaje, D., Mostert, L., Groenewald, J.Z., Crous, P.W., 2015. Phaeoacremonium: from esca disease to phaeohyphomycosis. Fungal Biol. 119, 759-783.

Grunwald, N.J., Martin, F.N., Larsen, M.M., Sullivan, C.M., Press, C.M., Coffey, M.D. Hansen, E.M., Parke, J.L., 2011. Phytophthora-ID.org: a sequence-based Phytophthora identification tool. Plant Dis. 95, 337-342.

Harris, D.J., 2003. Can you bank on GenBank? Trends Ecol. Evol. 18, 317-319.

Kaplan, J., Travadon, R., Cooper, M.L., Hillis, V., Lubell, M., Baumgartner, K., 2016. Identifying economic hurdles to early adoption of preventative practices: the case of trunk diseases in California winegrape vineyards. Wine Econ. Policy 5 , $127-141$.

Kuntzmann, P., Villaume, S., Larignon, P., Bertsch, C., 2010. Esca, BDA and Eutypiosis: foliar symptoms, trunk lesions and fungi observed in diseased vinestocks in two vineyards in Alsace. Vitis 49, 71-76.

Lamichhane, J.R., Venturi, V., 2015. Synergisms between microbial pathogens in plant disease complexes: a growing trend. Front. Plant Sci. 6, 385.

Larignon, P., Dubos, B., 2000. Preliminary studies on the biology of Phaeoacremonium. Phytopathol. Medit. 39, 184-189.

Lawrence, D.P., Travadon, R., Baumgartner, K., 2015. Diversity of Diaporthe species associated with wood cankers of fruit and nut crops in northern California. Mycologia 107, 962-940.

Lawrence, D.P., Travadon, R., Pouzoulet, J., Rolshausen, P.E., Wilcox, W.F. Baumgartner, K., 2017. Characterization of Cytospora isolates from wood cankers of declining grapevine in eastern North America, with the descriptions of two new Cytospora species. Plant Pathol. 66, 713-725.

Lorrain, B., Ky, I., Pasquier, G., Jourdes, M., Guerin-Dubrana, L., Gény, L., Rey, P. Donèche, B., Teissedre, P.-L., 2012. Effect of Esca disease on the phenolic and sensory attributes of Cabernet Sauvignon grapes, musts and wines. Aus. J. Grape Wine Res. 18, 64-72.

Marchi, G., Peduto, F., Mugnai, L., Di Marco, S., Calzarano, F., Surico, G., 2006. Some observations on the relationship of manifest and hidden esca to rainfall. Phytopathol. Medit. 45, 117-126.

Mostert, L., Groenewald, J.Z., Summerbell, R.C., Gams, W., Crous, P.W., 2006. Taxonomy and pathology of Togninia (Diaporthales) and its Phaeoacremonium anamorphs. Stud. Mycol. 54, 1-113.

Mugnai, L., Graniti, A., Surico, G., 1999. Esca (black measles) and brown woodstreaking: two old and elusive diseases of grapevines. Plant Dis. 83, 404-418.

Nilsson, R.H., Ryberg, M., Kristiansson, E., Abarenkov, K., Larsson, K.-H., Koljalg, U., 2006. Taxonomic reliability of DNA sequences in public sequence databases: a fungal perspective. PloS One 1, e59.

O'Donnell, K., Cigelnik, E., 1997. Two divergent intragenomic rDNA ITS2 types within a monophyletic lineage of the fungus Fusarium are nonorthologous. Mol. Phylogenet. Evol. 7, 103-116.

Pennycook, S., Samuels, G., 1985. Botryosphaeria and Fusicoccum species associated 
with ripe fruit rot of Actinidia deliciosa (kiwifruit) in New Zealand. Mycotaxon 24, 445-458.

Petzoldt, C.H., Moller, W.J., Sall, M.A., 1981. Eutypa dieback of grapevine: seasonal differences in infection and duration of susceptibility of pruning wounds. Phytopathology 71, 540-543.

Rolshausen, P.E., Urbez-Torres, J.R., Rooney-Latham, S., Eskalen, A., Smith, R.J., Gubler, W.D., 2010. Evaluation of pruning wound susceptibility and protection against fungi associated with grapevine trunk diseases. Am. J. Enol. Vit. 61, 113-119.

Rossman, A.Y., Palm-Hernández, M.E., 2008. Systematics of plant pathogenic fungi: why it matters. Plant Dis. 92, 1376-1386.

Sakalidis, M.L., Hardy, G.E.S.J., Burgess, T.I., 2011. Use of the genealogical sorting index (GSI) to delineate species boundaries in the Neofusicocccum parvumNeofusicoccum ribis species complex. Mol. Phylogenet. Evol. 60, 333-344.

Sakalidis, M.L., Slippers, B., Wingfield, B.D., Hardy, G.E.S.J., Burgess, T.I., 2013. The challenge of understanding the origin, pathways and extent of fungal invasions: global populations of the Neofusicoccum parvum- $N$. ribis species complex. Divers. Distrib. 19, 873-883.

Serra, S., Mannoni, M.A., Ligios, V., 2008. Studies on the susceptibility of pruning wounds to infection by fungi involved in grapevine wood diseases in Italy. Phytopathol. Medit. 47, 234-246.

Sipiora, M.J., Cuellar, S., 2014. Economic impact of Eutypa dieback. Wine Bus. 46-49. Monthly October:

Slippers, B., Crous, P.W., Denman, S., Coutinho, T.A., Wingfield, B.D., Wingfield, M.J., 2004. Combined multiple gene genealogies and phenotypic characters differentiate several species previously identified as Botryosphaeria dothidea. Mycologia 96, 83-101.

Sosnowski, M.R., Shtienberg, D., Creaser, M.L., Wicks, T.J., Lardner, R., Scott, E.S., 2007. The influence of climate on foliar symptoms of Eutypa dieback in grapevines. Phytopathology 97, 1284-1289.

Taylor, J.W., Jacobson, D.J., Kroken, S., Kasuga, T., Geiser, D.M., Hibbett, D.S., Fisher, M.C., 2000. Phylogenetic species recognition and species concepts in fungi. Fung. Gen. Biol. 31, 21-32.

Thiessen, L.D., Keune, J.A., Neill, T.M., Turechek, W.W., Grove, G.G., Mahaffee, W.F. 2016. Development of a grower-conducted inoculum detection assay for management of grape powdery mildew. Plant Pathol. 65, 238-249.

Travadon, R., Lawrence, D.P., Rooney-Latham, S., Gubler, W.D., Wilcox, W.W., Rolshausen, P.E., Baumgartner, K., 2015. Cadophora species associated with wood decay of grapevine in North America. Fung. Biol. 119, 53-66.

Travadon, R., Lecomte, P., Diarra, B., Lawrence, D.P., Renault, D., Ojeda, H., Rey, P., Baumgartner, K., 2016. Grapevine pruning systems and cultivars influence the diversity of wood-colonizing fungi. Fung. Ecol. 24, 82-93.

Trouillas, F., Gubler, W.D., 2010. Host range, biological variation, and phylogenetic diversity of Eutypa lata in California. Phytopathology 100, 1048-1056.

Trouillas, F.P., Pitt, W.M., Sosnowski, M.R., Huang, R., Peduto, F., Loschiavo, A., Savocchia, S., Scott, E.S., Gubler, W.D., 2011. Taxonomy and DNA phylogeny of Diatrypaceae associated with Vitis vinifera and other woody plants in Australia. Fung. Divers. 49, 203-223.

Trouillas, F.P., Urbez-Torres, J.R., Gubler, W.D., 2010. Diversity of Diatrypaceous fungi associated with grapevine canker diseases in California. Mycologia 102, 319-336.

Úrbez-Torres, J.R., Peduto, F., Smith, R., Gubler, W., 2013. Phomopsis Dieback: a grapevine trunk disease caused by Phomopsis viticola in California. Plant Dis. 97, 1571-1579.

Úrbez-Torres, J.R., 2011. The status of Botryosphaeriaceae species infecting grapevines. Phytopathol. Medit. 50, S5-S45.

Úrbez-Torres, J.R., Gubler, W.D., 2011. Susceptibility of grapevine pruning wounds to infection by Lasiodiplodia theobromae and Neofusicoccum parvum. Plant Pathol. 60, 261-270.

Úrbez-Torres, J.R., Haag, P., Bowen, P., Lowery, T., O'Gorman, D.T., 2015. Development of a DNA macroarray for the detection and identification of fungal pathogens causing decline of young grapevines. Phytopathology 105, 1373-1388.

Úrbez-Torres, J.R., Peduto, F., Striegler, R.K., Urrea-Romero, K.E., Rupe, J.C., Cartwright, R.D., Gubler, W.D., 2012. Characterization of fungal pathogens associated with grapevine trunk diseases in Arkansas and Missouri. Fung. Divers. 52, 169-189.

van Niekerk, J.M., Calitz, F.J., Halleen, F., Fourie, P.H., 2010. Temporal spore dispersal patterns of grapevine trunk pathogens in South Africa. Eur. J. Plant Pathol. 127, 375-390.

van Niekerk, J.M., Halleen, F., Fourie, P.H., 2011. Temporal susceptibility of grapevine pruning wounds to trunk pathogen infection in South African grapevines. Phytopathol. Medit. 50, S139-S150.

White, T.J., Bruns, T., Lee, S., Taylor, J., 1990. Amplification and direct sequencing of fungal and ribosomal RNA genes for phylogenetics. In: Innis, M.A., Gelfand, D.H., Sninsky, J.J., White, T.J. (Eds.), PCR Protocols: a Guide to Methods and Applications. Academic Press, Inc., San Diego, CA, pp. 315-322. 